\title{
Etik İklim Algısının Bireysel Yenilikçilik Üzerine Etkisinde Örgüt Kültürünün Düzenleyici Rolü
}

\author{
Edip ÖRÜCÜ ${ }^{1}$, Görkem AKGÜL ${ }^{2}$ ve Binnaz ÇINAR ${ }^{3}$
}

$\ddot{O} z$

$\mathrm{Bu}$ araştırmada akademisyenlerin etik iklim algısının bireysel yenilikçilik üzerine etkisinde örgüt kültürünün düzenleyici rolünün olup olmadığının belirlenmesi amaçlanmaktadır. Bu doğrultuda Konya ilinde eğitim öğretim veren bir yükseköğretim kurumundaki akademisyenlerin oluşturduğu örneklem grubundan kolayda örnekleme yöntemi ile anket yöntemi kullanılarak veri toplanmıştır. 207 katilımcıdan elde edilen verilere frekans analizi, tanımlayıc istatistikler ve korelasyon analizi, doğrulayıcı faktör analizi ve hiyerarşik regresyon analizi uygulanmıştır. Araştırma sonucunda; etik iklim algısının bireysel yenilikçiliği etkilediği ve bu etkide örgüt kültürünün düzenleyici etkiye sahip olduğu belirlenmiștir.

Anahtar Kelimeler: Etik İklim Algısı, Örgüt Kültürü, Bireysel Yenilikçilik.

\section{The Moderating Role of Organizational Culture in the Influence of Ethical Climate Perception on Individual Creativeness}

\section{Abstract}

This research is aimed to determine the moderating role of organizational culture in the influence of ethical climate perception of scholars on individual innovation. Data were collected through questionnaire from the sampling group determined by convenience sampling method and consisting of scholars from a university located in Konya. Frequency analysis, descriptive samplings and correlation analysis, confirmatory factor analysis, path analysis and hierarchical regression analysis were applied to the data collected from 207 participants. It is determined that, ethical climate perception affects the individual innovation and organizational culture has moderating influence on this effect.

Key Words: Ethical Climate Perception, Organizational Culture, Individual Innovation.

\section{Atıf İçin / Please Cite As:}

Örücü, E., Akgül, G. ve Çinar, B. (2020). Etik iklim algısının bireysel yenilikçilik üzerine etkisinde örgüt kültürünün düzenleyici rolü. Manas Sosyal Araștırmalar Dergisi, 9(2), 899-915.

\footnotetext{
${ }^{1}$ Prof. Dr. - Bandırma Onyedi Eylül Üniversitesi, İİBF, eörücü@bandirma.edu.tr ORCID: 0000-0002-3301-7496

2 Doktora Öğrencisi - Bandırma Onyedi Eylül Üniversitesi, Sosyal Bilimler Enstitüsü, akgulgrkm@gmail.com ORCID: 0000-0002-5758-6124

${ }^{3}$ Doktora Öğrencisi - Bandırma Onyedi Eylül Üniversitesi, Sosyal Bilimler Enstitüsü, binnazcinar62@gmail.com ORCID: 0000-0002-0323-9864
} 


\section{Giriş}

Kurumlar sahip oldukları etik değerler doğrultusunda hedefledikleri amaçları elde edebilirler ve değer yarabilirler. Bu etik değerlerin varlığı kurumların varlığını sürdürebilmesi ve değer yaratabilmesi açısından önemli bir etkendir. Kâr amacı güden ya da kâr amacı gütmeyen herhangi bir kurumdaki çalışanların, yöneticilerin gerçekleştirilecek olan eylemler ve projelerin etik değerler altında toplanması, bu kurumların hedefledikleri amaçları gerçekleştirmesinde yardımcı olacaktır. Aksi bir durumun yaşanması halinde bu kurumlarda etik değerlerin zarar görmesine kirlenmesine yol açacaktır (Yaman, Mermer ve Mutlugil, 2009). Kurumlarda etik değerlerde oluşan kirlenmenin temizlenmesi oldukça güçtür. Etik kuralların yer almadığı, geliştirilmediği bir kurumda bu kuralların uygulanabilmesi açısından ciddi sorunlar yaşanır. Bu sebeple kurum ortamında çatışmalar ve ikilemler de meydana gelir, etik kurallar konusunda netlik elde edilemez. $\mathrm{Bu}$ tür kurumlar içerisinde karmaşa ve kaosun ortaya çıkmasıyla çalşanlar üzerindeki verimlilik azalmaktadır. Elde edilen birikimler ve kurum imajinı yok olmasına sebep olacaktır. Aynı zamanda etik kuralların dikkate alınmaması ile maddi ve manevi açıdan maliyetler artacak ve kuruma zarar verecektir (Çelik, 2005).

Kurumda etik iklim kurallarının uygulanması konusunda yöneticilere büyük görev düşmektedir. Yöneticiler, alınacak kararların kurum içerisindeki etik boyutunu istintak etmek zorundadır. Akademisyenler ile ilişkilerin düzgün bir biçimde sürdürülmesi ve ciddi anlamda değer yaratılmasının sağlanması, yönetim tarafindan alınan kararların etik değerlere sahip olup olmadığına yöneliktir (Yılmaz, 2009). Kurumların kimliği ve imajı niteliğinde olan akademisyenlerin, ahlak ve sorumluluk çerçevesinde faaliyetlerini yürütebilmelerini sağlamak için kurumun olumlu etik iklim değerlerine sahip olmas1 gerekmektedir. Akademisyenler tarafindan olumlu bir şekilde algilanan etik iklim kurum kimliğini ve değerlerini pozitif etkileyeceği gibi, akademisyenlerin örgütsel bağlllı̆̆ını, yöneticiye duyulan güveni yükseltip; örgüt kültürleri ve aynı zamanda bireysel yenilikçi kimlikleri üzerinde olumlu etkileri ortaya çıkarmasında etkili olacaktır. Kurum yöneticileri, görev aldıkları kurumların etik değerlerini de yönetmeye ihtiyaç duymaktadırlar (Akbaş, 2010).

Etik iklim alg1sı, örgüt kültürü ve bireysel yenilikçilik kavramları üzerine ağıllı verilen bu araştırmada, kavramlar açıklanarak, bu kavramların literatürde yer alan diğer değişkenlerle ilişkisi incelenmiştir. Bunun neticesinde bağımlı değişken bireysel yenilikçilik davranışı bağımsız değişken etik iklim algısı ve düzenleyici değişken örgüt kültürü ile ilgili ulusal ve uluslararası yazında herhangi bir çalışmaya rastlanılmamıştır. Buradan hareketle, etik iklim algısının bireysel yenilikçilik üzerine etkisinde örgüt kültürünün düzenleyici rolü araştırmanın amacını oluşturmaktadır.

\section{Kavramsal Çerçeve}

\section{Etik İklim Algısı}

Etik iklim, 1980’lerin sonlarında Victor ve Cullen (1987-1988) tarafindan yapılan araştırmalar sonucunda ortaya atılmış olan bir kavramdır (Wimbush ve Shepard, 1994). Etik iklim, örgütlerin karşılaştıkları etik problemlerle nasıl başa çıkacaklarını ve bu süreç içerisinde neyin doğru neyin yanlış olduğunu yazılı, resmi ya da resmi olmayan kurallar ile belirlenmesi, etik açıdan doğru davranışın ne olduğunun örgüt içerisinde genel olarak algılanması olarak tanımlanmaktadır (Victor ve Cullen, 1988). Alan yazında etik iklim ile ilgili olarak pek çok tanım yer almaktadır. Schneider ve Rentsch'e (1988) göre işletmelerde çalışanlar açısından beklenen, desteklenen ve ödüllendirilen davranışlar olarak tanımlamışlardır. Etik iklim, örgütlerin etik problemleri nasıl çözüme kavuşturduğu ve bunun sonucunda çalışanlara örgüt içerisinde doğru davranışların neler olduğu hakkında karar vermeleri açısından bir yol çizmektedir (Deshpande, 1996; Weber ve Seger, 2002). Örgütlerin doğru davranışın ne olduğuna dair verecekleri cevaplar onların tüm değerlerini ifade etmekte ve etik iklimlerine katkı sağlamaktadır (Cullen, Victor ve Stephens, 1989).

Lopez, Babin ve Chung’a (2009) göre etik iklim, örgütlerde çalısanların davranış şekillerini, sorumluluklarının neler olduğunu, yanlışlarını ve doğrularını görmelerini ve davranışlarını ne kadar etik olarak algıladıklarını ifade eder. Etik iklim çalışanların karşıllaştıkları ahlaki durum karşısında "ne yapmalıyım" sorusuna cevap vererek, sorunların çözülmesine (Cullen, Parboteeah ve Victor, 2003), örgütlerdeki etik davranışların oluşmasında ve açıklanmasında yardımcı olur (Wimbush, Shepard ve Markham, 1997). Bu bağlamda örgütlerde yazılı olan veya olmayan bu etik davranışlar çalışanlar tarafindan algılanabilir (Akbaş, 2010). Çalışanların konumları, yaptıkları işler, çalışma süreleri gibi çeşitli faktörler etik iklimin farklı algılanmasına neden olabilir (Victor, Cullen 1988). Ayrıca örgütlerin etik olan ve olmayan 
davranışları net olarak belirtmesi çalıșanlar açısından olumlu tutumların geliştirilmesinde faydalı olmaktadır (Valentine ve Barnett, 2003). Örgütlerde etik iklimin var olması, çalışanların birlik, beraberlik, motivasyonunun yüksek olması (Dickson, Simith, Grojean ve Ehrhart, 2001), iş tatmini ve firma performansının artması (Weber ve Seger, 2002; Tsai ve Huang, 2008), ve örgütsel bağlllık ve işten ayrilmaların azalmasına neden olmaktadır (Schwepker, 2001; Valentine ve Barnett, 2003; Hunt, vd. 1989). Etik iklim, örgütsel davranış ve çıktılarının üzerinde doğrudan veya dolaylı olarak etkide bulunmaktadır (Ballı ve Ballı, 2017) ve örgütler için bir kontrol mekanizması olması açısından önemi gittikçe artmaktadır (Erdoğan, Kırılmaz ve Arslanoğlu, 2018). Örgüt içerisinde sağlanan etik iklime rağmen bazen çalışanlar tarafindan etik dışı davranışların baş göstermesi olası bir konudur. Söz konusu durumda etik iklimi benimseyen çalşanlar tarafindan duruma müdahale edilmesi ve gerekli bilgilerin üst yönetime iletilmesi sağlanmakta (Günluk, Özer ve Özcan, 2017) bunun sonucunda örgütsel kârlllı̆̆a önemli bir katk1 sağlanmaktadır (Bartels, Harrick, Martell ve Strickland, 1998). Ayrıca çalışanların kişisel çıkarları, ekip çıkarlarının olması, bireysel arkadaşlıklar, faaliyet etkinliği, kişisel ahlak, sosyal sorumluluk ve benzeri faktörlerin örgütlerde baş göstermesi durumunda farklı etik iklimlerin oluşması etkili olabilmektedir (Savran, 2007). Örgütlerde etik iklimin sağlanmaması ya da bozulması durumunda çalışanların yönetime karşı olan güvenleri olumsuz olarak etkilenmektedir (Agrawal, 2017; Erdoğan, Kırılmaz ve Arslanoğlu, 2018).

\section{Örgüt Kültürü}

Örgüt kültürü, 1980'li dönemlerde bilim insanları tarafından irdelenmesiyle ortaya çıkmıştır. Bu dönemde sanayileşmenin görüldüğu ve geliştiği 1700 ve 1800'lü yıllar temel alındığında örgüt kültürü kavramının yeni bir kavram olduğu ifade edilmektedir (Yücel ve Koçak, 2016). Bu tarihlerde incelenmesinin nedeni ise; Japonların üst düzey özelliklere sahip örgüt yapılarından etkilenen Amerikalı işletmeler, onların örgüt vizyonunu, misyonunu, felsefesini ve o örgütlerin başarıya doğru yol almasındaki kültürel değerlerin peşine düşerek, aynı popülerliği elde etmeye çalışmışlardır (Sökmen, Benk ve Gayaker, 2017). Bu kavram; sosyal psikoloji, antropoloji, sosyoloji, iktisat, örgütsel davranış, insan bilimi ve hukuk gibi farklı bilim dalları tarafından incelendiği için farklı tanımlar alında toplanmaktadır.

Örgüt kültürü, bir organizasyon çalısanlarının fikir ve düşüncelerini ortaya çıkaran davranışlar, inançlar ve değerler sistemi olarak tanımlanmaktadır (Karcıoğlu, 2001; Yaman ve Ruçlar, 2014). Aynı zamanda örgüt kültürü çalışanlar açısından belirsizliklerin azalması ve işlerin ne şekilde ve nasıl yapılacağ1 konusunda kolaylıklar sağlamaktadır. Bu tanımlar ışığında örgüt külttürü, bir organizasyon tarafından benimsenen normlar, sembol, inançlar ve algı düzeni şeklinde özetlenebilir (İşcan ve Timuroğlu, 2007; Bitsani, 2013).

Örgüt kültürü, çalışan tutum ve davranışları üzerinde son derece etkili olmaktadır. Aynı zamanda örgüt kültürü çalışanlar açısından belirsizlikleri en aza indirilerek işi ne şekilde ve nasıl yapacakları konusunda kolaylık sağlamaktadır. Bununla birlikte, örgüt kültürünün potansiyel olarak negatif fonksiyonu da bulunmaktadır. Örgüt kültür yapısı ile çevrenin nitelikleri birbirleriyle uyumlu bir halde değil ise, bu durum örgütün başarısında olumsuz etkilere neden olabilecektir. Bu sebeple örgüt kültürünün çevre ile uyumlu olduğu süreçte fonksiyonlar olumlu bir şekilde gerçekleştirilebilecektir (Özkalp ve Kırel 2001). Örgüt içinde çalışanların başarı sergilemeleri için öğrendikleri inanç ve değerler yeterli olmamaktadır. Çalışanlar örgüt kültürünü benimsemeliler ve örgütün bir parçası olabilmelilerdir. Örgüt kültürüne karşı uygun tutum ve davranışlar sergileyen çalışanlar, ödül ve terfi için temel sağlarlar (Robbins, 2003).

Literatürde, örgüt kültürü ile ilgili olarak yapılmış çeşitli sınıflandırmalara tabi araştırmalar yer almaktadır. Yapılan bu araştırmalar içinde en yaygın kullanılan sınıflandırmanın klan kültür, pazar kültür, hiyerarşi kültür ve adhokrasi kültür olarak dört alt boyutu oluşturacak şekilde olduğu görülmüştür (Yalçınsoy ve Zincirkıran, 2016).

\section{Klan Kültürü}

Klan örgüt kültürüne sahip olan örgütler geniş bir aileye benzer, örgütsel atmosferde çalışanlar ve yöneticiler arasında aileye benzer bir ilişki vardır. Çalışanlar örgüte çok şey katarlar, çalışanların kendilerini geliştirmesi, yeni fikirlere açılık, örgüt içerisinde ortak değerlerin benimsenmesi, takım ruhu ve çalışması, örgütsel bağlllık klan kültürünün genel özellikleridir. Liderlik emir komuta değil yol gösterici niteliktedir, yönetimsel açıdan ortak görüş birliği ve katılım önemlidir. Çalışanların bağlllğ̆1 ve güveni klan kültürünün temelidir. Bu kültürde çalısanların birbirlerine destek olmaları, moral vermeleri ve tüketicilerin ilgisini 
çekmek başarının göstergesidir (Cameron ve Quinn, 1992'den aktaran: Ergün, 2007; Erdem, Adıgüzel ve Kaya, 2010; Öcal ve Ağca, 2010; Özdevecioğlu ve Akın, 2013; Yalçınsoy ve Zincirkıran 2016).

\section{Adhokrasi Kültür}

Girişimci kültür olarak da ifade edilen adhokrasi kültüründe örgüt içerisinde yeniliğe açıklık ve risk alma gibi özellikler yer almaktadır. Otorite karizma temelinde kazanılır ve örgütlerin kendilerine has değerleri göz önünde bulundurularak kullanılır (Cameron ve Quinn, 1992'den aktaran: Ergün, 2007; Erdem, vd. 2010; Öcal ve Ağca, 2010; Özdevecioğlu ve Akın, 2013; Yalçınsoy ve Zincirkıran 2016). Adhorasi kültürünün temelinde girişimcilik ve yenilik yatmaktadır (Cameron ve Freeman, 1991). Bu kültüre sahip olan örgütler kendilerini hızla yenileyebilen, değişen şartlara çabuk uyum gösterebilen dinamik ve uzmanlaşmış bir yapıya sahip olmakla beraber örgüt içerisinde verilecek olan karalar yaratıcı ve risk alan liderler tarafından genellikle sezgisel olarak alınır (Hult, Ketchen ve Nichols, 2002). Örgütler tarafindan çalısanların fikirlerini açıkça ifade etmeleri, kararlara dahil edilmeleri sağlanır. Örgütler uzun dönemde faaliyetlerini genişletmeye ve yeni kaynaklar elde etmeye değer verir (Cameron ve Quinn, 1992'den aktaran: Ergün, 2007; Erdem, vd. 2010; Öcal ve Ağca, 2010; Özdevecioğlu ve Akın, 2013; Yalçınsoy ve Zincirkıran 2016).

\section{Pazar Kültürü}

Pazar kültürünü benimseyen işletmeler gerçekleştirilen işe ve bu işin sonuçlarına yönelmiş işletmelerdir. Bu sebeple, çalş̧anlar arasında bir yarış ve mücadele olması için destek verilir. Bunun sonucunda başarılı çalışanlar ödüllendirilir. İşletme başarısı ise, pazar payına ve rekabet üstünlük derecesine göre değerlendirilmektedir (Yücel ve Koçak, 2016). Bu kültürde rekabet, amaca ulaşabilme ve dış ortam ile iletişim en belirgin faktörlerdir. Pazar kültürünü destekleyen işletmeler için dış çevre ile başa çıkabilmek ve pazarda liderliği sağlayabilmek önemli bir unsurdur (Balogh, Gaal and Szabo, 2011). Pazar kültürünü benimseyen işletmelerde bireyler başarı odaklı olabilmeleri için yöneticiler tarafından teşvik edilirler. İşletme yöneticileri iş faaliyetlerinin devam ettirilebilmesini sağlamak için katı kurallara sahiptirler. Örgüt tarzı, güçlü ve devam ettirilebilir rekabetçiliği içerir. Pazar kültürünü benimseyen örgüt yapıları aynı zamanda diş çevrede yer alan faktörlere odaklanırlar (Cameron ve Quinn, 1992: 37'den aktaran: Erdem, Orhan ve Kaya, 2010).

\section{Hiyerarşi Kültür}

Hiyerarşi kültür, bürokratik kuralların yer aldığı bir kültür tipidir. Bürokratik kurallar, işletmeyi bir arada tutar ve bütünleştirici işlevi yerine getirir. İşletmenin başarısı, etkinlik ve verimlilik esasına dayanır. Örneğin, düşük maliyetlerin olması işletme için değerli başarı unsurudur (Öcal ve Ağca, 2010). Hiyerarşi kültüründe yeterlilik işletme performansı için ölçülebilen önemli bir kriterdir. Dolayısıyla işletme, bürokratik özelliğe ne kadar yaklaşırsa o derece etkili olmaktadır. Başka bir ifade ile bir işletme uzmanlaşmış ve merkezi olursa o derece iyidir ifadesi kullanılabilir. Özetlemek gerekirse, bu kültürün önemsediği ana yapı, yasal veya mantıksal çerçeve içinde olmalıdır (Cameron ve Whetten, 1996). Kurum içindeki roller, kurumda çalışanlar için belirlenmektedir. Kurum, bu rollere uyum sağlayabilecek bireyleri işe almaktadır (Ergün, 2007).

\section{Bireysel Yenilikçilik}

Yenilikçi birey, bir konu, düşünce ya da uygulamanın getireceği risklerden kaçınmadan yeni tecrübelere duyarlıdır, önemli ya da değerli gördüğü için kendini yenilemekten geri durmaz. Buna göre, bireysel yenilikçilik herhangi bir yeniliği geliştirmek, benimsemek veya uygulamak şeklinde ifade edilebilir (Yuan ve Woodman, 2010). Handa ve Gupta (2009), Rogers (1983) ve Oğuztürk ve Türkoğlu (2004)'na göre yenilikçilik, yeni ve farklı bir duruma karşı meydana gelen algıları/tepkileri ifade eden bir bireysel fark değişkenidir.

Bireysel yenilikçilik, "yeni olan şeylere karşı bireylerin risk alma, kabullenme, uyum sağlama, tolerans gösterme ve yeni olan şeye karşı deneyime açık olma" durumlarını ifade etmektedir (Demiraslan ve Usluel, 2008). Bireylerin yenilikçi davranışları konusundaki çoğu ampirik araştırma iş yerinde bireysel yenilikçiliğe ve bireysel yaratıcıllğga odaklanmıştır (Goepel, Hölzle ve Knyphausen-Aufseb, 2012). Bireysel yenilikçilik, bireyin yaratıcılı̆̆ıla bağlantılıdır. Herkesin, doğal karakterine ve risk alma eğilimine dayanan yaratıcılık düzeyi vardır. İnsanlar daha yaratıcı düşünmek ve yaratıcı düşünce stratejilerini uygulamak üzere eğitilebilmektedir. Vaka incelemeleri, deneyler ve çeşitli araştırma yöntemleri kullanarak teorisyenler, bireylerin yenilik bileşenlerini ortaya koymaya çalışmışır. Bu bileşenlerin bilgi (bireyin yaratıcı çabasını 
destekleyen anl ayış), yaratıcı düşünme (insanların problemlere yaklaşma tarzı) ve motivasyon (yaratıcılıkta anahtar faktör) olduğu ifade edilmektedir (Tewari, 2011).

Roger (2003)'ın çalışmasında bireyler kişilik özelliklerine göre yenilikçilik açısından beş farklı sınıfa ayrılmıştır. Bu sınıflama bireylerin yenilikleri benimseme derecelerine göre yapılmış ve bireylerin yenilikçilik düzeyleri yenilikçiler, öncüler, sorgulayıcılar, kuşkucular ve gelenekçiler şeklinde sıralanmıştır. Öncüler, toplumun diğer bireylerine yenilikler konusunda yol gösterirler, genellikle teknoloji odaklı, sosyal ve eğitim seviyesi yüksek bireylerdir. Sorgulayıcılar, yeniliklere karşı tedbirli davranırlar ve risk alma eğilimleri düşüktür. Kuşkucular, genellikle toplumun yenilikleri benimsemesini bekleyen, yeniliklere şüpheci ve çekingen bir tavır gösteren, yaş ortalaması yüksek ve eğitim seviyesi düşük bireylerdir. Gelenekçiler, yeniliği en son benimseyen, değişime karşı önyargılı ve dirençli bireylerdir (Rogers, 2003). Yenilikçiler, yenilikle ilgili sürekli bilgi arayışı içerisinde olduklarından dolayı kitle iletişim araçlarını yoğun bir şekilde takip etmekte, yerel bilgi kaynaklarının dışında büyük ölçekli küresel sosyal ağlardan yararlanmakta ve içinde bulundukları sosyal sistemin dişındaki yenilikler hakkında bilgi edinmektedir (Rogers, 1995).

\section{Söz Konusu Kavramlara Yönelik Literatürde Yer Alan Çalışmalar}

\section{Etik İklim Algısı ile İlgili Çalışmalar}

Ahmetoğulları ve Çatı (2017) yılında yaptıkları, "STK Mensuplarının Etik İklim Algısının Örgütsel Bağlılık Aracılığıyla Bireysel Performanslarına Etkisi” adlı çalışmalarında sivil toplum kuruluşları mensuplarının etik iklim algılarının örgütsel bağlllık yoluyla bireysel performansına etkisini incelemişlerdir. Bu kapsamda Düzce ve Bolu ilindeki 300 STK mensubu araştırmanın örneklemini oluşturmuş ve toplanan veriler Yapısal Eşitlik Modelli (YEM) ile test edilmiştir. Doğrulayıcı faktör analizi (DFA) sonuçlarına göre iyiliksever etik iklim, normatif etik iklim, örgütsel bağllık ve bireysel performans arasında anlamlı bir ilişki tespit edilmiştir. Yapılan Yol Analizine göre iyiliksever etik iklim değişkenin kurumsal bağllık aracı değişkeni yoluyla bireysel performans değişkenini açıkladığı ve normatif etik iklim değişkenin örgütsel bağlılık aracı değişkeni yoluyla dolaylı olarak bireysel performans değişkenini nispi olarak açıkladığı çıan sonuçlar arasında yer almaktadır.

Erdoğan, Kırılmaz ve Arslanoğlu (2018), araştırmalarında bir kamu hastanesinde etik iklim algısı ile enformel iletişim arasındaki ilişkinin ne yönde olduğunu belirlemeyi amaçlamışlardır. Bu bağlamda basit rastgele örneklem yöntemi uygulayarak, kamu hastanesinde hekim dışında çalışan personelin 236'sından topladıkları verileri tanımlayıcı istatiksel yöntemler, keşfedici faktör analizi, güvenilirlik analizi, bağımsız örneklerde t-testi, one way anova testi, korelasyon ve regresyon analizlerine tabi tutmuşlardır. Araştırma sonuçları, enformel iletișimin etik iklim algısını etkilediği; çalışanlar arasında etik iklim algısının medeni duruma göre farklllıklar gösterdiği; enformel iletişime göre medeni durum, meslek ve yaşa göre farklılıkların olduğunu gözlenmektedir. Bu sonuçlara ek olarak etik iklim algisı yüksek olan çalışanların etik dışı bir durum ile karşılaştıklarında bu durumu yönetime formel ve enformel iletişim kanallarını kullanarak bilgilendirebileceklerini ifade etmişlerdir.

Aydan ve Kaya (2018) tarafından gerçekleştirilen çalışmada, hemşirelerin etik iklim algılarının örgütsel güven düzeyleri üzerindeki etkisini incelemişlerdir. Ankara'da bir üniversite hastanesinde klinik ve polikliniklerde çalışan 167 hemşireden veriler toplanmıştır. Değişkenler arasındaki etkiyi ölçebilmek için korelasyon ve regresyon analizleri uygulanmıştır. Bunları sonucunda hemşirelerin etik iklim algısı ve örgütsel güven düzeyleri arasında anlamlı bir ilişki saptanmıştır.

Emül ve Demirel (2018) sağlık çalışanlarının değerlendirmelerine göre etik iklim algısının hasta güvenliği kültürü üzerindeki etkisini belirlenmeyi amaçlamışlardır. Elâzığ il merkezinde bulunan 4 kamu, 4 özel toplam 8 hastane bünyesinde çalışan 346 sağlık çalışanı çalışmanın örneklemini oluşturmuştur. Değişkenler arasındaki neden sonuç ilişkisini açıklamak için regresyon analizi uygulanmıştır. Katılımcıların etik iklim algisının hasta güvenliği kültürü üzerindeki etkisinin pozitif yönde ve kısmi olduğu tespit edilmiştir.

Ballı ve Ballı (2017) yaptıkları çalışmalarında otel işletmelerindeki çalışanların, etik iklim algı düzeylerinin incelenmesi amaçlanmışlardır. Bu doğrultuda Adana, Ankara, İstanbul ve İzmir illerinde faaliyet gösteren dört ve beş yıldızlı otel işletmelerindeki 794 çalışandan veriler toplanmıştır. Açıklayıcı, doğrulayıcı faktör analizi, ANOVA ve T-testi analizleri uygulanarak veriler analiz edilmiştir. Çalışanların etik iklim alg1 düzeylerinin yüksek olduğu ve ayrıca çalışanların eğitim düzeyinin, çalıştıkları otelin yıldız 
sayısının, personel sayısının ve sahiplik durumunun algılanan etik iklim üzerinde anlamlı farklılıklar gösterdiği çıkan sonuçlar arasında yer almaktadır.

Karaca, Özkan ve Küçükkelepçe (2018)'de doğum ve pediatri hastanesinde çalışan hemşirelerin ve ebelerin etik iklim algılarını belirlemeyi amaçlamışlardır. Türkiye'nin Güneydoğu'sundaki doğum ve pediatri hastanesinde çalışan 115 ebe ve hemşireden veriler toplanmıştır. T-test, ANOVA, Mann-WhitneyU ve Kruskal Wallis analizleri kullanılarak veriler test edilmiştir. Katılımcıların demografik özellikleri (yaş, meslek ve medeni durum), iş yerleri ve etik iklim algıları arasında fark olmadığı ve hemşirelerin ve ebelerin iş tatmini ve etik iklim algıları arasında anlamlı bir fark olduğu tespit edilmiş̧ir.

Choe, Choong ve Tan (2017) "Etik İklimin Örgütsel Bağlllı̆ga Etkisi: Malezya'daki Yüksek Öğrenim Kurumları Üzerine Bir Uygulama” isimli çalışmalarında etik iklim ve örgütsel bağllık arasındaki ilişkiyi incelemeyi amaçlamışlardır. Veriler Malezya'daki 5 kamu 5 özel yükseköğrenim kurumunda çalışan 244 akademik personelden toplanmıştır. Önerilen araştırma modeli yapısal eşitlik analizine tabi tutulmuştur. Etik iklimin iyiliksever ve ilkesel alt boyutlarının örgütsel bağllık ile pozitif, egoizm boyutunun ise negatif ilişkili olduğu gözlenmiştir.

Liu, ZhaoRui Li, Zhou ve Tian (2018) yaptıkları çalışmalarında örgütsel kimlik ve whistle-blowing ilişkisinde algılanan etik iklim ve proaktif kişiliğin aracı etkisini ölçmeyi amaçlamışlardır. Çin’in Jiangsu eyaletinde yer alan 152 şirket içerisinden 44 tanesi çalışmaya destek vermiştir. Bu şirketlerde görev alan 900 çalışandan veriler anket aracılığılya toplanmıştır. Araştırma sonuçları, örgütsel kimlik ile whistle-blowing arasında pozitif bir ilişkinin olduğunu bu ilişkide algılanan etik iklim ve proaktif kişiliğin aracı etkisi tespit edilmiştir. Örgütsel kimlik, proaktif kişiliğe sahip olan ve güçlü bir etik iklimi algilayan kişilerin whistleblowing niyetlerini olumlu yönde etkilemektedir.

Biçer (2017), etik iklim ve örgütsel öğrenmenin yenilikçi davranışlar üzerindeki etkilerin uygulamadaki yansımalarını ortaya çıarmayı amaçlamıştır. Bu amaç doğrultusunda 2016'da Türkiye'nin en büyük 500 sanayi kuruluşunda çalışan 582 çalışan örneklemini oluşturmaktadır. Bu çalş̧mada, Kaiser-Meyer-Olkin $(\mathrm{KMO})$, Bartlett's test, Pearson korelasyon analizi, regreyon analizleri uygulanmıştır. Araştırma sonuçlarına göre, çalışanların etik iklim algılamalarının istatistiksel olarak anlamlı ve pozitif yönlü örgütsel öğrenme düzeylerini ve eğilimlerini etkilediğini, çalışanların etik iklim algılamalarının istatistiksel olarak anlamlı seviyede yenilikçi davranışlarını etkilediğini göstermektedir.

\section{Bireysel Yenilikçilik ile İlgili Çalışmalar}

Olpak, Arıcan ve Baltac1 (2018) tarafından devlet üniversitesinde eğitim fakültesinde ilköğretim matematik programında öğrenim gören 46 öğrenciden üzerinden veriler toplanmıştır. Bu araştırmanın amacı, öğretmen adaylarının akran öğretimi yöntemine yönelik memnuniyet düzeylerinin öğrenme yaklaşımlarına ve bireysel yenilikçilik özelliklerine göre anlamlı bir farklılık olup olmadığının incelenmesidir. Araştırma bulgularında öğretmen adaylarının akran öğretimi yöntemine yönelik memnuniyet düzeylerinin öğrenme yaklaşımlarına ve bireysel yenilikçilik özelliklerine göre anlamlı bir farkll1ık göstermediği belirlenmiştir.

Akram (2016), Çin’in telekomünikasyon sektöründe çalışan 235 birey üzerinde bireysel yenilikçiliğin iş davranışlarında örgütsel adaletin etkileri irdelenmiştir. Araştırma sonucunda örgütsel adalet alt boyutları dağıtım, prosedür, etkileşim ve zamanın bireysel yenilikçiliği güçlü ve olumlu bir şekilde etkilediği tespit edilmiştir.

Thurlings, Evers ve Vermeulen (2015) tarafindan 396 dergi makalesi ve tezler üzerinde bir inceleme yapılmıştır. Bu sistematik literatür taramasında, eğitim kurumları için bir bireysel yenilikçi davranış modeli geliştirilmiştir. Bu incelemeye dayanarak, geleceğin eğitim kalitesini arttırmak için öğretmenlerin yenilikçi davranışları hakkında daha fazla araştırma yapılması gerekliliği tespit edilmiştir.

Bhaduri ve Kumar (2011) bireysel yenilikçiliği kabul edenlerde içsel motivasyon etkisinin incelendiği çalışmada yeni fikirlerin geliştirilmesi ve denenmesi aşamasında içsel motivasyonun etkisi olduğu sonucuna ulaşılmıştır. Lyons ve Schneider (2005)'e göre, pozitif duygular yaratıc1lı̆̆ geliştirmekte ve böylece bireysel yenilikçiliğe de yatkınlık sağlamaktadır. Bunlara ek olarak Park (2005) kaliteli duygusal ortamın verimliliği ve yaratıcilı̆̆ı pozitif yönde etkilediğini bulmuştur. Ayrıca, Goleman (1998)'a göre, yüksek duygusal zekâya sahip bireyler müzakerede ve problem çözmede daha başarılı olmakta ve bunlar da yaratıcı düşüncelerin temelini oluşturmaktadır. Yaratıcı düşüncelerin üretimi de bireysel yenilikçilik sürecinin ilk aşaması olarak kabul edilmektedir. 


\section{Örgüt Kültürü ile İlgili Çalışmalar}

Özen Kutanis, Özsoy, Karakiraz, Aras, Erol ve Uslu (2015), örgüt kültürü ile ilgili yapılmış lisansüstü tezlerin incelenmesi için bir çalışma gerçekleştirmişlerdir. Araştırma kapsamında yüksek lisans ve doktora tezi olmak üzere 183 tez incelenmiştir. Tezler detaylı incelendiğinde tipoloji geliştirme, boyut geliştirme, ölçek geliştirme, örgüt kültürü gibi değisşkenlere çoğu tezde yer verilmediği belirlenmiştir. Yöntem açısından genellikle nicel yöntemler uygulandığı, nitel ve karma yöntemlerden az sayıda faydalanıldığı tespit edilmiştir.

Yaman ve Ruçlar (2014), öğretim elemanlarının örgütsel sessizlik ve örgüt kültürü algılarının incelenmesini amaçlamışlardır. Araştırma örneklemini 2012-2013 öğretim yllında Sakarya Üniversitesi’nde bulunan altı fakültede eğitim veren 253 öğretim elamanı oluşturmaktadır. Araştırma sonucunda akademisyenlerin örgütsel sessizlik algıları ve örgüt kültürü algıları arasında anlamlı bir ilişki olduğu saptanmışıır. Çalışmanın bir diğer sonucu ise, örgütsel sessizlik ve örgüt kültürü alt boyutları arasında negatif bir ilişkinin olduğu belirlenmiştir.

Örgüt kültürünün otantik liderlik üzerindeki etkisini incelemek amaciyla Azanza, Antonio ve Molero (2013) bir araştırma hazırlamışlardır. Bu çalışma için 571 çalışandan veriler elde edilerek, çoklu regresyon analizi uygulanmıştır. Araştırma sonucunda, örgüt kültürünün otantik liderliği pozitif etkilediği belirlenmiştir. Aynı zamanda örgüt kültürünün iş tatmini de pozitif ve anlamlı bir şekilde etkilediği tespit edilmiştir.

Jacobs, Mannion, Davies, Harrison, Konteh ve Walshe (2013), İngiliz hastanelerinde üst düzey yönetim takım kültürü ve örgütsel performans arasındaki ilişki probit ve multinomial logit modelleri kullanılarak incelemişlerdir. Üst yönetim takım kültürünü ölçmek için onaylanmış bir kültür derecelendirme aracı olan Rekabet Değerleri Çerçevesi kullanılmıştır. Örgütsel performans ölçeği çeşitli göstergeler kullanılarak değerlendirilmiş ve üst düzey yönetim takım kültürü ile örgütsel performans arasında ilişki olduğu sonucuna ulaşılmıştır.

\section{Etik İklim Algısı, Bireysel Yenilikçilik ve Örgüt Kültürü ile İlgili Çalışmalar}

Etik iklim ve örgüt kültürü, organizasyonlarda yenilik ile ilişkili olan örgütsel değerler aracıllğıyla, yeniliği benimseyen çalsşanlar arasında örgütsel bağllığı oluşturmasıyla çalışanların yenilikçi davranışlarıyla ilişkilidir (Hartmann, 2006). Organizasyonlarda yönetici ve çalışanların yenilikçi davranışları benimsemesi ve uygulamasında örgüt iklim faktörlerinin etkisi bulunmaktadır (West ve Wallace, 1991; West ve Anderson, 1996).

Çelen (2016), etik liderlik yönünden örgüt kültürü ve etik iklim ilişkilerini konu alan bir araştırma gerçekleştirmiştir. Çalışma kapsamında lisansüstü düzeyde örgüt kültürü ile ilgili yapılmış araştırmalar incelenmiştir. YÖK Tez Merkezi verilerine göre, 2000-2015 yllları arasında konuyla ilgili tüm sektörlerde yapılmış araştırma toplamı 225 ve bunlar arasından 180'i yüksek lisans, 45’i ise doktora düzeyinde olduğu belirtilmiştir. Önemli bölümü erişime kapalı bu araştırmalar içinde işletme bilim dalı kapsamında gösterilenler 64'tür. Çalışma bulgularında işletmelerin örgüt kültürü algısında kadın ve erkeklerin algılamasında istatistiksel olarak anlamlı farklllığa rastlanmamıştır. Kamu çalışanları ile özel sektör çalışanlarına bakıldığında ise örgüt kültürü algısında anlamlı fark vardır. Bu alg1 Kamu sektöründe çalşanlarda daha yüksekken, özel sektör çalısanlarında daha düşüktür. Bundan farklı olarak lisansüstü eğitimin de örgüt kültürü algısını artırdığı sonucuna varılmıştır.

Hogan ve Coote (2014) tarafindan yapılan araştırmada özellikle hizmet firmalarında yeniliği destekleyen örgüt kültür süreçlerinin izlenebilirliği ölçülmüştür. Schein’in kavramsal modeline dayanan ampirik bir model hazırlanmıştır. Yaklaşık olarak 100 hukuk fakültesi müdüründen toplanan veriler ile model test edilmiştir. Araştırma bulguları yazılan hipotez ilişkilerini desteklemektedir. Araştırma sonucunda örgüt kültürünün yenilikçi davranışını, kısmen firma performansını etkilediği sonucuna ulaşılmıştır.

Topcu, Gürsoy ve Taşbaşı (2013) ise, etik iklim algısının bireysel yenilikçilik davranışlarına etkisinde hizmetkâr liderliğin rolünün incelemişlerdir. KKTC'de faaliyette bulunan konaklama işletmelerinde görev alan toplam 254 kişiden anket yöntemiyle veriler toplanmıştır. Araştırma bulgularında çalşsanların etik iklim algılarının bireysel yenilikçi davranışlar üzerinde etkili olduğu belirlenmiştir. Ayrıca, bu etkileşimde hizmetkâr liderliğin de aracılık rolünün yer aldığ1 saptanmıştır. 
Akkoç (2012) ise, "Gelişim Kültürü ve Etik İklimin Yenilikçiliğe Etkisinde Dağgtım Adaletinin Rolü" isimli araştırmasında çalışanların yenilikçi davranışlarında, gelişim kültürü ve etik iklimin rolü irdelenmiştir. Aynı bu etki üzerinde dağıtım adaletinin aracı rolü incelenmiştir. Havacıllk ve uzay sanayi sektöründe gerçekleştirilen çalısmada, 576 çalışanın tutumları ölçülerek analizler yapıllmıştır. Araştırma sonucunda, gelişim kültürü ve etik iklimin yenilikçi davranışı olumlu yönde etkilediği ve bu etkiye dağıtım adaletinin aracllık etkisinin olduğu saptanmıştır.

Bu bilgiler ışığında aşağıda yer alan araştırma hipotezleri ve modeli oluşturulmuştur.

$\mathbf{H}_{1}$ : Etik ilkim algısının bireysel yenilikçilik üzerinde etkisi vardır.

$\mathbf{H}_{2}$ : Etik iklim algısının bireysel yenilikçilik üzerine etkisinde örgüt kültürü düzenleyici role sahiptir.

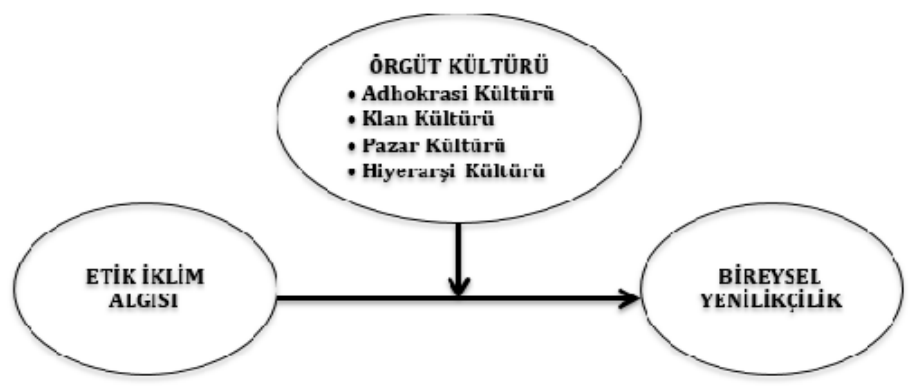

Şekil 1. Arastırmann Modeli

\section{Yöntem}

\section{Araştırmanın Amacı}

$\mathrm{Bu}$ araştırmanın amacı, bir yükseköğretim kurumunda görev alan akademisyenlerin etik iklim algılamalarının bireysel yenilikçi davranışları üzerine etkisinde örgüt kültürünün düzenleyici rolünün belirlenmesidir.

\section{Evren- Örneklem}

Araştırmanın evrenini Konya ilinde eğitim-öğretim veren bir yükseköğretim kurumunun yaklaşık 300 akademik çalışanı oluşturmaktadır. Bu çerçevede $\mathrm{p}$ ve q değerleri 0,5 ve 0,5 , hoşgörü $\mathrm{E}=0,05$ ve $\% 95$ güven aralığında 250 kişiyi $\% 95$ güven aralığında 168 kişinin temsil etme yeteneğine sahip olduğu hesaplanmıştır (Altunışık, Coşkun, Bayraktaroğlu ve Yıldııım, 2010; Gürbüz ve Şahin, 2017). Anket yöntemiyle kolayda örnekleme tekniği kullanılarak toplam 215 katılımcıdan anketlere geri dönüş sağlanmıştır. Veri girişi sırasında yanlış ve eksik doldurulduğu tespit edilen 8 adet anket formu örneklem dışında tutulmuştur. Toplam 207 adet veri analize tabi tutulmuştur. Veriler Kasım 2018 tarihinde toplanmiştır.

\section{Veri Toplama Araçları}

Araştırmada kullanılan değişkenlerin ölçülebilmesi amacıyla literatürde geniş bir tarama yapılmıştır ve elde edilen ölçeklerden araştırma için uygun oldukları düşünülenler uyarlanmıştır. Araştırmanın amacına uygun olarak hazırlanmış olan anket formunun ilk bölümünde katılımcılara bilgi vermek amacıyla giriş kısmı yer almaktadır. İkinci bölüm içerisinde demografik değişkenlere yer verilmiştir. Üçüncü bölümde ise, araştırmanın modelini oluşturan etik iklim algısı, bireysel yenilikçilik ve örgüt kültürü değişkenlerini ölçmeye dayalı sorular bulunmaktadır. Demografik değişkenler dışındaki anket formu içerisindeki yer alan sorular 5'li Likert yöntemine (1=kesinlikle katılmiyorum; $5=$ kesinlikle katıllyorum) göre cevaplandırılmıştır.

Etik iklim algısı ölceği (7 İfade) Qualls ve Puto'nun (1989) ölçeğini temel alarak Schwepker, Ferrell ve Ingram, (1997) tarafından geliştirilmiştir. Araştırmada Biçer (2005) tarafindan Türkçe’ye uyarlanan hali kullanılmıştır. Tek boyutlu olan ölçekte ters soru bulunmamaktadır. Etik iklim algısı ulusal yazında; Karadut (2014), Toker (2015), Demirdağ ve Ekmekçioğlu (2015), Akçakanat ve Uzunbacak (2018) tarafindan kullanılmıştır. 
Örgüt kültürü̈ ölceği (24 ifade) Cameron ve Quinn (1999) tarafindan geliștirilmiştir ve adhokrasi kültürü (6 ifade), klan kültürü (6 ifade), pazar kültür (6 ifade) ve hiyerarşi kültürü (6 ifade) olmak üzere dört alt boyuttan oluşmaktadır. Bu araştırmada Yücel ve Koçak (2016) tarafindan Türkçe'ye uyarlanan hali kullanılmıştır. Örgüt kültürü ölçeği ulusal yazında; Çıraklı, Gözlü ve Dalkılıç (2017) tarafından kullanılmıştır. Ölçek içerisinde ters soru yer almamaktadır.

Bireysel yenilikeçilik ölçeğ (20 ifade) Hurt, Joseph ve Cook (1977) tarafından geliştirilmiş olup tek boyuttan oluşmaktadır. Kılıçer ve Odabaşı (2010) tarafından Türkçe'ye uyarlanmıştır. Bireysel yenilikçilik ölçeği ulusal yazında Işıı ve Meriç (2015), Kilıç, (2015), Çuhadar, Bülbül, Ilgaz (2013), Kert ve Tekdal (2012) tarafından çalışmalarında kullanılmıştır. Ölçek içerisinde 6 ters soru bulunmaktadır.

\section{Verilerin Analizi}

Araştırma kapsamında verilerin analizini gerçekleştirmek için SPSS 16 (Statistical Package for the Social Science) ve AMOS 25 (Analysis of Moment Structures) programları kullanılmıstır.

\section{Bulgular}

Araştırma yöntemi ile elde edilen verilere öncelikli olarak katılımcıların demografik özelliklerini tespit etmek amacıyla frekans analizi uygulanmıştır. Daha sonra araştırmada kullanılan etik iklim algısı, bireysel yenilikçilik ve örgüt kültürü ölçeklerinin güvenirliliği için Cronbach’s Alpha katsayısı incelenmiştir.

Araştırmada kullanılan değişkenlerin normal bir dağılım sergileyip sergilemediklerini test etmek amacıyla Kolmogorov-Smirnov ( $>00,05)$ testi ve çarpıklık ve basıklı ölçebilmek için Skewness-Kurtosis $(-1,5$ ile $+1,5)$ testleri yapılmıştır. Yapılan bu analizler sonucunda Kurtosis ve Skewness oranlarının -1,5 ile $+1,5$ arasında ve $\mathrm{p}>0,05$ anlamllık seviyesinde olduğundan dağllımın anlamlı ve normal olduğu belirlenmiştir. [İklim Algısı=Kurtosis ve Skewness (,197/-,806), Bireysel Yenilikçilik=Kurtosis ve Skewness (1,542/-1,092), Adhokrasi Kültürü=Kurtosis ve Skewness (-,541/-,544), Klan Kültürü=Kurtosis ve Skewness (,110/-,763), Pazar Kültürü=Kurtosis ve Skewness (,117/-,638), Hiyerarşi Kültürü=Kurtosis ve Skewness (,125/-,729)]. Modeldeki değişkenlerin test edilebilmesi amacıyla tanımlayıcı istatistikler ve korelasyon analizi, doğrulayıcı faktör analizi ve hiyerarşik regresyon analizi uygulanmıştır.

\section{Demografik Bulgular}

Araştırmaya katılanlar demografik olarak incelendiğinde; katılımcıların \%54,6'sının erkeklerden \%44,4'ünün kadınlardan; yaş gruplarına göre \%44,9'unun 24-35 yaş aralığındakilerden, \%28'nin 36-47, $\% 18,8$ 'nin 48-59, \%6,8'nin de 60 yaş ve üzerindekilerden ve \%68,1'inin evlilerden, \%31,4'ününde bekârlardan oluştuğu gözlenmektedir. Katılımcıların \%23,2'sinin iktisadi ve idari bilimler fakültesinde, \%18,4'ünün mühendislik fakültesinde, $\% 16,9$ 'unun tıp fakültesinde, $\% 12,1$ 'inin güzel sanatlar ve tasarım fakültesinde, \%10,1'inin sosyal ve beşerî bilimler fakültesinde, \%8,7'sinin sağllk hizmetleri meslek yüksekokulunda ve \%8,7’sinin de sağlık bilimleri yüksekokulunda çalıştığ1 belirlenmiştir. Akademik ünvanlarına göre katıllımcıların \%32,4'ü araştırma görevlisi, \%23,2'si doktor öğretim üyesi, \%18,4'ü doçent doktor, \%15,5’i öğretim görevlisi ve \%10,6's1 profesör doktordan oluşmaktadır. Ankete katılanların $\% 38,6$ 'si 1-5 yll, \%28,5'i 6-10 yll, \%12,1', 20 yll ve üzeri, \%9,2'si 11-15 yll ve \%8,2'de 16-20 yll arasinda deneyime sahiptir. Analizler incelendiğinde demografik değişkenler içerisinde yaşta 3 kişinin, cinsiyette 2 kişinin, medeni durumda 1 kişinin, fakültede 4 kişinin ve deneyimde 7 kişinin soruları cevapsız bıraktı̆̆1 tespit edilmiştir. Cevapsız kalan soruların yüzdelik değerleri Tablo 1'de yer almaktadır. 
Tablo 1. Demografik Değiskentere Ait Analizler

\begin{tabular}{|c|c|c|c|c|c|}
\hline Yass & $n$ & $\%$ & Akademik Ünvan & $n$ & $\%$ \\
\hline $24-35$ & 93 & $\overline{44,9}$ & Öğretim Görevlisi & 32 & 15,5 \\
\hline $36-47$ & 58 & 28,0 & Araştırma Görevlisi & 67 & 32,4 \\
\hline $48-59$ & 39 & 18,8 & Doktor Öğretim Üyesi & 48 & 23,2 \\
\hline 60 ve üzeri & 14 & 6,8 & Doçent Dr. & 38 & 18,4 \\
\hline Cevapsiz & 3 & 1,4 & Profesör Dr. & 22 & 10,6 \\
\hline \multirow[t]{2}{*}{ Toplam } & 207 & 100,0 & Cevapsiz & $\ldots$ & $\ldots$ \\
\hline & & & Toplam & 207 & 100,0 \\
\hline Cinsiyet & $n$ & $\%$ & Medeni Durum & $n$ & $\%$ \\
\hline Kadin & 92 & $\overline{44,4}$ & $\overline{\text { Evli }}$ & 141 & 68,1 \\
\hline Erkek & 113 & 54,6 & Bekâr & 65 & 31,4 \\
\hline Cevapsiz & 2 & 1,0 & Cevapsiz & 1 &, 5 \\
\hline Toplam & 207 & 100,0 & Toplam & 207 & 100,0 \\
\hline Fakülte & $n$ & $\%$ & Deneyim & $n$ & $\%$ \\
\hline Sağllk Hizmetleri MYO & 18 & 8,7 & $\overline{1-5}$ & 80 & 38,6 \\
\hline Tip Fakültesi & 35 & 16,9 & $6-10$ & 59 & 28,5 \\
\hline Sosyal ve Beşeri Bilimler Fakültesi & 21 & 10,1 & $11-15$ & 19 & 9,2 \\
\hline Sağllk Bilimleri Yüksekokulu & 18 & 8,7 & $16-20$ & 17 & 8,2 \\
\hline İktisadi ve İdari Bilimler Fakültesi & 48 & 23,2 & 20 ve üzeri & 25 & 12,1 \\
\hline Mühendislik Fakültesi & 38 & 18,4 & Cevapsiz & 7 & 3,4 \\
\hline Güzel Sanatlar ve Tasarım Fakültesi & 25 & 12,1 & Toplam & 207 & 100,0 \\
\hline Cevapsiz & 4 & 1,9 & & & \\
\hline Toplam & 207 & 100,0 & & & \\
\hline
\end{tabular}

\section{Güvenilirlik Analizi}

Araştırma kapsamında yapılan güvenilirlik analizi neticesinde Cronbach's Alpha katsayıları incelenmiştir. Bu değerin en az 0,60 olması gerekmektedir (Gürbüz ve Şahin, 2017). Kullanılan üç ölçeğinde katsayıları incelendiğinde, güvenilirlik seviyelerinin iyi olduğu belirlenmiştir. Tüm ölçeklere ait güvenilirlik analizi sonuçları Tablo 2'de sunulmaktadır.

Tablo 2. Güvenilirlik Analizleri

\begin{tabular}{lcc}
\hline Ölçek & Iffade Sayıs 1 & Cronbach's Alpha \\
\hline Etik İklim Algisı & 7 &, 931 \\
Bireysel Yenilikçilik & 20 &, 829 \\
Örgüt Kültürü & 24 &, 955 \\
• Adhokrasi Kültürü & 6 &, 926 \\
• Klan Kültürü & 6 &, 920 \\
• Pazar Kültür & 6 &, 881 \\
• Hiyerarşi Kültürü & 6 &, 903 \\
\hline
\end{tabular}

\section{Araştırma Değişkenlerine İlişkin Tanımlayıcı İstatistikler ve Korelasyon Katsayıları}

Etik iklim algısı, bireysel yenilikçilik ve örgüt kültürü değişkenlerine ait tanımlayıcı istatistikler ve aralarındaki ilişkiye yer veren Pearson Korelasyon analizi bulguları Tablo 3’te yer almaktadır. Bu sonuçlara göre etik iklim alg1sı ve bireysel yenilikçilik $(\mathrm{r}=, 352, \mathrm{p}>0.01)$, etik iklim alg1s1 ve örgüt kültürü $(\mathrm{r}=, 466$, p>0.01), bireysel yenilikçilik ve örgüt kültürü arasında istatistiksel açıdan anlamlı bir ilişki bulunmuştur. Tüm değişkenlere ilişkin aritmetik ortalama değerleri incelendiğinde akademisyenlerin etik iklim alg1sının olumlu ve diğer iki değişkene oranla 3,6404 bir ortalamaya sahip olduğu görülmektedir. Bunu takiben bireysel yenilikçiliğe ait ortalama değeri 3,6051 ve örgüt kültürü değişkeninin ortalama değeri 3,5213'tür. Akademisyenler tarafindan algılanan bu ortalama değerler incelendiğinde bireysel yenilikçiliğe ait ortalama değerinin örgüt kültürü ortalama değerinden daha yüksek olduğu tespit edilmiştir.

Tablo 3. Tammlayuc İstatistikler ve Korelasyon Katsaynlar

\begin{tabular}{llllll}
\hline & \multicolumn{3}{c}{ Korelasyon Katsayılant } & \multirow{2}{*}{ Ortalama } & \multirow{2}{*}{ Standart Sapma } \\
\cline { 2 - 4 } & $(1)$ & (2) & & 3,6404 &, 91677 \\
\hline Etik İklim Algısı & 1 & & 3,6051 &, 50674 \\
Bireysel Yenilikçilik &, $352^{* *}$ & 1 & 3,5213 &, 75678 \\
Örgüt Kültürü &, $466^{* *}$ &, $189^{* *}$ & 1 & 3 \\
\hline
\end{tabular}

\footnotetext{
** Korelasyonlar 0.01 düzeyinde anlamlı
} 


\section{Doğrulayıc1 Faktör Analizi}

Doğrulayıcı faktör analizi, çalışmada kullanılan verilerin daha önce kurgulanmış olan faktör yapısı ile uyumlu olup olmadığını ortaya çıkarmak için değişkenlerin faktör yapısı test edilir (Meydan ve Şeşen, 2015: 57). Doğrulayıcı faktör analiz sonuçlarına Tablo 4’te yer verilmiştir.

Tablo 4. Doğrulaync Faketör Analizi Sonuclar

\begin{tabular}{|c|c|c|c|}
\hline $\begin{array}{c}\text { Araştırmada Kullanilan } \\
\text { Sorulat }\end{array}$ & Standardize Faktör Yükleri & $C r$ & $P$ \\
\hline \multicolumn{4}{|l|}{ Etik İklim Algısı } \\
\hline EIA1 & 0,879 & \multirow{7}{*}{7,932} & 0,001 \\
\hline EIA2 & 0,907 & & 0,001 \\
\hline EIA3 & 0,918 & & 0,001 \\
\hline EIA4 & 0,887 & & 0,001 \\
\hline EIA5 & 0,614 & & 0,001 \\
\hline EIA6 & 0,635 & & 0,001 \\
\hline EIA7 & 0,616 & & 0,001 \\
\hline \multicolumn{4}{|l|}{ Bireysel Yenilikçilik } \\
\hline BY1 & 0,448 & \multirow{20}{*}{1,585} & 0,001 \\
\hline BY2 & 0,725 & & 0,001 \\
\hline BY3 & 0,751 & & 0,001 \\
\hline BY4 & 0,428 & & 0,001 \\
\hline BY5 & 0,706 & & 0,001 \\
\hline BY6 & 0,462 & & 0,001 \\
\hline BY7 & 0,291 & & 0,001 \\
\hline BY8 & 0,443 & & 0,001 \\
\hline BY9 & 0,643 & & 0,001 \\
\hline BY10 & $-0,175$ & & 0,001 \\
\hline BY11 & 0,696 & & 0,001 \\
\hline BY12 & 0,449 & & 0,001 \\
\hline BY13 & 0,240 & & 0,001 \\
\hline BY14 & 0,432 & & 0,001 \\
\hline BY15 & 0,480 & & 0,001 \\
\hline BY16 & 0,416 & & 0,001 \\
\hline BY17 & $-0,045$ & & 0,001 \\
\hline BY18 & 0,667 & & 0,001 \\
\hline BY19 & 0,502 & & 0,001 \\
\hline BY20 & 0,234 & & 0,001 \\
\hline \multicolumn{4}{|l|}{ Örgüt Kültürü } \\
\hline AK1 & 0,822 & \multirow{24}{*}{5,802} & 0,001 \\
\hline AK2 & 0,907 & & 0,001 \\
\hline AK3 & 0,791 & & 0,001 \\
\hline AK4 & 0,811 & & 0,001 \\
\hline AK5 & 0,871 & & 0,001 \\
\hline AK6 & 0,738 & & 0,001 \\
\hline KK1 & 0,826 & & 0,001 \\
\hline KK2 & 0,824 & & 0,001 \\
\hline KK3 & 0,814 & & 0,001 \\
\hline KK4 & 0,836 & & 0,001 \\
\hline KK5 & 0,740 & & 0,001 \\
\hline KK6 & 0,748 & & 0,001 \\
\hline PK1 & 0,630 & & 0,001 \\
\hline PK2 & 0,827 & & 0,001 \\
\hline PK3 & 0,812 & & 0,001 \\
\hline PK4 & 0,863 & & 0,001 \\
\hline PK5 & 0,742 & & 0,001 \\
\hline PK6 & 0,542 & & 0,001 \\
\hline HK1 & 0,660 & & 0,001 \\
\hline HK2 & 0,856 & & 0,001 \\
\hline HK3 & 0,807 & & 0,001 \\
\hline HK4 & 0,726 & & 0,001 \\
\hline HK5 & 0,777 & & 0,001 \\
\hline HK6 & 0,855 & & 0,001 \\
\hline
\end{tabular}


Doğrulayıcı faktör analizinde, iyi bir yapının sağlanması için Composite Reliability (CR) katsayılarının 0,70 ve üzerinde olması gerekmektedir. Bununla birlikte 0,70 eşiği önemli bir eşik olarak değerlendirirlerken 0,50 ve altı değerlerin uygun olmadığ1 ifade edilmektedir (Hair, Lukas, Robert ve LeeLukas, 2014). Tablo 4'te sunulduğu üzere, tüm boyutlar için CR değeri 0,70'in üzerindedir. Faktör yükleri açısından araştırmada kullanılan değişkenlerin ideal yapının üzerinde veya ideal yapıya uygun değerlere sahip olduğu ifade edilebilir.

Tablo 5: Doğrulaync Faktör Analizi Model Uyum Değerleri

\begin{tabular}{|c|c|c|c|}
\hline Uyum Ölçütü & $\dot{I}$ yi Uyum & Kabul Edilebilit Uyum & Model Uyum Değerlert \\
\hline \multicolumn{4}{|l|}{ Etik İklim Algısı } \\
\hline $\mathrm{CMIN} / \mathrm{DF}\left(X^{2} / \mathrm{df}\right)$ & $\mathrm{X}^{2} / \mathrm{df} \leq 3$ & $4 \leq X^{2} / d f \leq 5$ & 2,17 \\
\hline RMSEA & RMSEA $\leq 0,05$ & $0,06<$ RMSEA $<0,08$ & 0,07 \\
\hline TLI & $\mathrm{TLI} \geq 0,95$ & $0,90<$ TLI $<0,94$ & 0,98 \\
\hline CFI & $C F I \geq 0,97$ & $C F I \geq 0,95$ & 0,99 \\
\hline GFI & $G F I \geq 0,90$ & $0,85<\mathrm{GFI}<0,89$ & 0,97 \\
\hline \multicolumn{4}{|l|}{ Bireysel Yenilikçilik } \\
\hline CMIN/DF $\left(X^{2} / \mathrm{df}\right)$ & $\mathrm{X}^{2} / \mathrm{df} \leq 3$ & $4 \leq \mathrm{X}^{2} / \mathrm{df} \leq 5$ & 1,56 \\
\hline RMSEA & RMSEA $\leq 0,05$ & $0,06<$ RMSEA $<0,08$ & 0,05 \\
\hline TLI & TLI $\geq 0,95$ & $0,90<$ TLI $<0,94$ & 0,91 \\
\hline CFI & $C F I \geq 0,97$ & $C F I \geq 0,95$ & 0,95 \\
\hline GFI & $G F I \geq 0,90$ & $0,85<\mathrm{GFI}<0,89$ & 0,90 \\
\hline \multicolumn{4}{|l|}{ Örgüt Kültürü } \\
\hline CMIN/DF $\left(X^{2} / \mathrm{df}\right)$ & $\mathrm{X}^{2} / \mathrm{df} \leq 3$ & $4 \leq \mathrm{X}^{2} / \mathrm{df} \leq 5$ & 1,64 \\
\hline RMSEA & RMSEA $\leq 0,05$ & $0,06<$ RMSEA $<0,08$ & 0,05 \\
\hline TLI & TLI $\geq 0,95$ & $0,90<\mathrm{TLI}<0,94$ & 0,95 \\
\hline CFI & $C F I \geq 0,97$ & $C F I \geq 0,95$ & 0,96 \\
\hline GFI & $G F I \geq 0,90$ & $0,85<\mathrm{GFI}<0,89$ & 0,86 \\
\hline
\end{tabular}

Kaynak: Meydan ve Şeşen (2015)

DFA sonucunda ortaya çıkan model uyum değerleri ve eşik değerler Tablo 5'te sunulmuştur. DFA sonuçlarına göre çıkan model değerlerinin çoğunun iyi uyum ve kabul edilebilir uyum değerleri arasında olduğu tespit edilmiştir.

\section{Hiyerarşik Regresyon Analizi}

Araştırma hipotezleri $\left(\mathrm{H}_{1}\right.$ : Etik ilkim algısının bireysel yenilikçilik üzerinde etkisi vardır ve $\mathrm{H}_{2}$ : Etik iklim algısının bireysel yenilikçilik üzerine etkisinde örgüt kültürü düzenleyici role sahiptir) testi için hiyerarşik regresyon analizi kullanılmıştır. Araştırma sonuçları Tablo 6'da sunulmuştur.

Tablo 6. Hiyerarsitk Regresyon Analiz̨i Sonuclar

\begin{tabular}{|c|c|c|c|c|c|c|c|}
\hline Model & Bağıms1z Değişkenler & Beta & $t$ & $F$ & Sig. & $R^{2}$ & $\begin{array}{c}\text { Düzenleyici } \\
R^{2}\end{array}$ \\
\hline \multirow[t]{2}{*}{1} & Sabit & & 21,358 & 28,989 & 000 & \multirow[t]{2}{*}{,124 } & \multirow[t]{2}{*}{, 120} \\
\hline & Etik Iklim Alg1s1 & ,352 & 5,384 & Sig. 0,00 &, 000 & & \\
\hline 2 & $\begin{array}{l}\text { Sabit } \\
\text { Etik İklim Alg1sı } \\
\text { Örgüt Kültür }\end{array}$ & $\begin{array}{r}337 \\
, 032\end{array}$ & $\begin{array}{c}16,592 \\
4,551 \\
0,437\end{array}$ & $\begin{array}{c}14,533 \\
\text { Sig. } 0,00\end{array}$ & $\begin{array}{l}, 000 \\
, 000 \\
, 663\end{array}$ & ,125 & ,116 \\
\hline \multirow[t]{4}{*}{3} & Sabit & & 14,097 & & 000 & \multirow{4}{*}{, 247} & \multirow{4}{*}{,236 } \\
\hline & Etik İklim Alg1s1 & ,396 & 5,691 & 22,239 &, 000 & & \\
\hline & Örgüt Kültürü & ,122 & 1,730 & Sig. 0,00 & ,085 & & \\
\hline & Etik İklim Alg1si*Örgüt Kültürü & ,373 & 5,751 & & 000 & & \\
\hline
\end{tabular}

Tablo 6'da hiyerarşik regresyon analizi sonuçlarına göre, Model 1'de bağımsız değişken etik iklim algısı ile bağımlı değişken bireysel yenilikçilik davranışına olan etkisi incelenmiştir. Aralarındaki neden sonuç ilişkisinin anlamlı ve olumlu olduğu $(\beta=0,352, \mathrm{p}<0,05)$ tespit edilmiştir. Buna göre $\mathrm{H}_{1}$ hipotezi kabul edilmiştir.

Model 2'de analize örgüt kültürü değişkeninin eklenmesiyle etik iklim algısının bireysel yenilikçilik üzerinde etkisinin olduğu, fakat örgüt kültürünün bireysel yenilikçilik üzerinde $(\beta=0,032, p<0,05)$ etkisi olmadığ1 tespit edilmiştir. 
Model 3'e bakıldığında, etik iklim alg1sı ile düzenleyici değişken olan örgüt kültürünün değerlerinin çarpılmasıyla (Etik İklim Algısı*Örgüt Kültürü) elde edilen etkileşim değişkeni analize eklenmiştir. Etkileşim teriminin eklenmesi ile açıklanan varyans miktar1 R2 $=0,125$ 'ten üçüncü modelde $\mathrm{R} 2=0,247$ 'ye yükselmiştir. Etik iklim alg1sı ile örgüt kültürü etkileşiminin bireysel yenilikçilik üzerinde $(\beta=0,373$, $\mathrm{p}<0,05)$ pozitif ve anlamlı bir etkisinin olduğu saptanmıştır. Bu kapsamda $\mathrm{H}_{2}$ kabul edilmiştir.

\section{Tartışma, Sonuç ve Öneriler}

Sosyal sistem içerisinde yer alan yükseköğretim kurumları, akademik zaman diliminde belirledikleri amaç ve hedeflere ulaşabilmek için akademisyenleri ve öğrencileri ile bir bütün halinde faaliyetlerini devam ettirmektedirler. Kurumun amaçları doğrultusunda hedeflerini yönetim tarzı, organizasyon yapısı, örgüt kültürü, eğitim politikaları, bilgi yönetimi, etik yönetim ve akademisyenlerin etik iklim alg1lamaları ve bireysel yenilikçi davranışları gibi birçok unsur doğrudan ya da dolaylı olarak etkileyebilmektedir. Buna bağlı olarak, bu çalışmada yükseköğretim kurumlarında görev alan akademisyenlerin etik iklim algılarının bireysel yenilikçilik üzerine etkisine örgüt kültürünün düzenleyici etkisi incelenmiştir. Araştırmanın amacının gerçekleştirilebilmesi için, Konya ilinde eğitim öğretim veren bir yükseköğretim kurumunda 207 kişiden toplanan veriler değerlendirilmiştir.

Çalışma kapsamında oluşturulan hipotezler hiyerarşik regresyon analizi ile test edilmiştir. Literatürdeki bulgulara göre Topcu vd. (2013) yaptıkları araştırmalarında çalışanların etik iklim algılarının bireysel yenilikçi davranışlar üzerinde etkili olduğu, ayrıca Akkoç’un (2012) araştırmasında ise etik iklimin yenilikçi davranışı olumlu yönde etkilediği sonucuna varılmıştr. $\mathrm{Bu}$ araştırmada elde edilen bulgulara göre literatürdeki sonuçlar desteklenmiştir. Etik iklim algısının bireysel yenilikçiliği etkilediği $\left(\mathrm{H}_{1}\right)$, akademisyenlerin etik iklim algısının bireysel yenilikçilik üzerinde etkisinde örgüt kültürünün düzenleyici rolünün olduğu $\left(\mathrm{H}_{2}\right)$ belirlenmiştir. Bu sonuçlar doğrultusunda, akademisyenlerin bağlı bulundukları kurum içerisinde etik olan ve etik olmayan davranışların kurum ve yöneticiler tarafindan net olarak belirtilmesinin akademisyenler üzerinde olumlu tutum ve davranışlara neden olduğu ifade edilebilir. Ayrıca kurumlarda etik iklimin var olması, akademisyenlerin birlik ve beraberlik, performans ve motivasyonların olumlu bir şekilde etkilediği ve bunun da bireysel yenilikçilik üzerinde doğrudan ve dolaylı olarak bir etkiye sahip olacağı söylenebilir.

$\mathrm{Bu}$ araştırma kapsamında incelenen konu ile ilgili olarak kurumlara ve uygulayıcılara öneriler sunulmuştur. Örgüt içerisinde etik iklim kurallarının örgüt faaliyetlerine uygun olarak belirlenmesi ve çalsşanlara net olarak ifade edilip, uygulanması hem çalışanlar hem yöneticiler hem de örgüt açısından verimli sonuçlar doğurabileceği söylenebilir. Akademisyenlerin bireysel yenilikçi davranışları ve örgütün sahip olduğu kültür yapısının (adhokrasi kültür, klan kültür, pazar kültür ve hiyerarşi kültür) gerçekleştirilecek bilimsel çalışmalarda etkili olabileceği ifade edilebilir. Yükseköğretim kurumlannda etik iklim algisının ve örgüt kültürünün bir arada bulunması ve benimsenmesi akademisyenlerin bireysel yenilikçi davranışlarını geliştirebilir. Bu kapsamda akademisyenlerin hem eğitim hem de bilimsel çalışmalarda verimlilikleri artabilir. Ayrıca örneklem sayısı artırılarak kamu ve özel sektör üzerinde karşılaştırma yapılabilir. Bununla birlikte yükseköğretim kurumlarında yer alan idari personel örnekleme katılarak performans değerlendirmesi incelenebilir. Bu araştırmada kullanılan etik iklim algısı ve bireysel yenilikçilik arasındaki ilişkide farklı düzenleyici etkiye sahip olabilecek değişkenlerde kullanılması önerilebilir. Aynı zamanda örgüt kültürünün alt boyutlarının (adhokrasi kültür, klan kültür, pazar kültür ve hiyerarşi kültür) tek tek düzenleyici etkileri araştırlabilir.

\section{Etik Beyan}

“Etik İklim Algısının Bireysel Yenilikçilik Üzerine Etkisinde Örgüt Kültürünün Düzenleyici Rolü” başlıklı çalışmanın yazım sürecinde bilimsel, etik ve alıntı kurallarına uyulmuş; toplanan veriler üzerinde herhangi bir tahrifat yapılmamış ve bu çalışma herhangi başka bir akademik yayın ortamına değerlendirme için gönderilmemiştir.

\section{Kaynakça}

Agrawal, R. K. (2017). Do ethical climates impact trust in management? A study in Indian context, International Journal of Organizational Analysis, 25(5), 804-824.

Ahmetoğulları, K. ve Kahraman Ç. K. (2017). STK mensuplarının etik iklim algısının örgütsel bağlllık aracıllğılla bireysel performanslarına etkisi. Mehmet Akif Ersoy Üniversitesi Sosyal Bilimler Enstitüsü Dergisi, Cilt.9(20), 283-313. 
Akçakanat, T. ve Uzunbacak, H. (2018). Algılanan örgütsel etik iklim ile örgütsel dışlanma arasındaki ilişki ve demografik değişkenlere göre farklılıkların incelenmesi. VI. International Multidisciplinary Congress of Eurasia, Social and Educational Sciences, 176-183.

Akkoç, İ. (2012). Gelişim kültürü ve etik iklimin yenilikçiliğe etkisinde dağıtım adaletinin rolü. Uluslararası Alanya İsletme Fakültesi Dergisi, 4(3), 45-60.

Akram, T. (2016). The effects of organizational justice on the innovative work behavior of employees: An empirical study from China. Journal of Creativity and Business Innovation, 2, 114-126.

Altunışık R., Coşkun R., Bayraktaroğlu S. ve Yıldırım E. (2010). Sosyal Bilimlerde Araştırma Yöntemleri SPSS Uygulamal. Sakarya Yayıncilik. Sakarya.

Aydan, A. ve Kaya, A. (2018). Hemşirelerin etik iklim algılarının örgütsel güven düzeyleri üzerindeki etkisi. Hacettepe Sağllk İdaresi Dergisi, 21(2), 199-216.

Azanza, G., Moriano, J. A. ve Molero, F. (2013). Authentic leadership and organizational culture as drivers of employees' saticfaction. Jounrla of Work and Organiational Psychology, 29, 45-50.

Ballı, E. ve Ballı, K. A. İ. (2017). Otel çalışanlarının örgütsel etik iklim algılarının incelenmesi. Sosyal ve Beşeri Bilimleri Dergisi, Cilt 9(2).

Balogh, A., Gaal, Z. ve Szabo, L. (2011). Relationship between organizational culture and cultural intelligence. Management \& Marketing Challenges for The Knowledge Society, 6(1), 95-110.

Bartels, L. K., Harrick, E., Martell, K. ve Strickland, D. (1998). The relationship between ethical climate and ethical problems within human resource management. Journal of Business Ethics, 17, 799-804.

Bhaduri, S. ve Kumar, H. (2011). Extrinsic and intrinsic motivations to innovate: Tracing the motivation of 'grassroot' innovators in India. Mind \& Society, 10(1), 27-55.

Biçer, M. (2005). Satıs elemanlarmın is tatmini, örgütsel bağhll̆ğ ve işten aymlma niyetinin etik iklim ile ilişkisi: Sigorta ve ilas sektörlerinde bir araştırma. (Yayınlanmış Yuiksek Lisans Tezi). Çukurova Üniversitesi Sosyal Bilimler Enstitüsü, Adana.

Biçer, M. (2017). Etik iklim, örgütsel ögrenme ve yenilikęi davranış iliş̧kisi üz̨erine bir araştırma. (Yayınlanmamış Doktora Tezi). Osmaniye Korkut Ata Üniversitesi Sosyal Bilimler Enstitüsü, Osmaniye.

Bitsani, E. (2013). Theoretical approaches to the organizational culture and the organizational climate: Exploratory research examples and best policies in health care services. Journal of Human Resource Management, 1(4), 48-58.

Cameron K. S. ve Tschirhart, M. (1992). Postindustrial environments and organizational effectiveness in colleges and universities. The Journal of Higher Education, 63(1), 87-108.

Cameron, K. S. ve Whetten, D. A. (1996). Organizational effectiveness and quality: The second generation. Handbook of Theory and Research, 11, 265-306.

Cameron, K. S. ve Quinn, R. E. (1999). Diagnosing and changing organizational culture. Reading, MA: Addison-Wesley.

Çelen, B. C. (2016). Etik liderlik açısından örgüt kültürü ve etik iklim ilişkileri. INTOCBEPS II; International Turgut Ozal Congress on Business, Economics and Political Science, 14-16 April, Ankara, 72-81.

Choe, K. L., Choonh, Y. O. ve Tan, L. P. (2017). The impact of ethical climate on organizational commitment: A study of Malaysian higher learning institutions. Global Business and Management Research: An International Journal, Vol. 9(1), 208-217.

Çıraklı, Ü., Gözlü, M. ve Dalkılıç, S. (2017). Hastane personellerinin örgüt kültürü tipi algısının incelenmesi: Yozgat'ta yer alan iki hastanede bir uygulama. Cankirn Karatekin Üniversitesi İktisadi ve İdari Bilimler Fakültesi Dergisi, Cilt 7(1), 33-59

Cullen, J. B., Victor. B. ve Stephens, C. (1989). An ethical weather report: Assessing the organization's ethical climate. Organizational Dynamics, 50-62.

Cullen J. B., Parboteeah K. P. ve Victor, B. (2003). The effects of ethical climates on organizational commitment: A two-study analysis. Journal of Business Ethics, 46(2), 127-141.

Demirağ, G. E. ve Ekmekçioğlu, E. B. (2015). Etik iklim ve etik liderliğin örgütsel bağl1lı üzerine etkisi: Görgül bir araştırma. Gaði Üniversitesi İktisadi ve İdari Bilimler Fakuiltesi Dergisi, 17(1),197-216.

Demiraslan, Y. ve Usluel K. Y. (2008). ICT integration processes in Turkish schools: Using activity theory to study 1ssues and contradictions. Australasian Journal of Educational Technology, 24(4), 458-474.

Deshpande, S. P. (1996). The impact of ethical climate types on facets of job satisfaction: An empirical investigation. Journal Of Business Ethics, 15, 655- 660.

Dickson, M. W., Simith, B. D., Grojean, M. W. ve Ehrhart, M. (2001). An organizational climate regarding ethics: The outcome of leader values and the practices that reflect them. The Leadership Quarterly, 12, 197-217.

Emül, E. ve Demirel, E. T. (2018). Etik iklim algısının hasta güvenliği kültürü üzerine etkisi: Elazığ örneği. Turkish Studies, Volume 13/7, Winter 2018, p. 83-122 DOI Number: http://dx.doi.org/10.7827/TurkishStudies.13044 ISSN: 1308-2140, Ankara-Turkey.

Erdem, E., Adıgüzel, O. ve Kaya, A. (2010). Akademik personelin kurumlarına ilişkin algıladıkları ve tercih ettikleri örgüt kültürü tipleri. Erciyes Üniversitesi İktisadi ve İdari Bilimler Fakültesi Dergisi, 36, 73-88.

Erdoğan, M. Kırılmaz, H. ve Arslanoğlu, A. (2018). Enformel iletişimin etik iklim alg1sı üzerine etkisi: Bir kamu hastanesi örneği. Sağllk. Akademisyenleri Dergisi, 5(2), 109-118.

Ergün, E. (2007). Kurum kültürünü analiz etmede Quinn ve Cameron’un rekabetçi değerler analizi. 15. Yönetim ve Organizasyon Kongresi, 266-271. 
Goepel, M. Hölzle, K., ve Knyphausen-Aufseb, D.Z. (2012). Individuals' innovation response behaviour: A framework of antecendents and opportunities for future research. Creativity and Innovation Management, 21(4), $412-426$.

Güçlü, N. (2003). Örgüt kültürü. Gazi Üniversitesi Sosyal Bilimler Dergisi, 23(2), 61-85.

Günluk M., Özer, G. ve Özcan M. (2017). Etik iklim ve örgütsel vatandaşlık davranışı ilişkisinde örgütsel bağl1lığın ara değişken etkisi: Muhasebe meslek mensupları üzerinde bir araştırma. AİÜ Sosyal Bilimler Enstitüsü Dergisi, 17(2), 83-103.

Gürbüz, S. ve Şahin, F. (2017). Sosyal bilimlerde araștırma yöntemleri. Seçkin Yayıncılık Ankara.

Handa, M. ve Gupta, N. (2009). Gender influence on the innovativeness of young urban Indian online shoppers. The Journal of Business Perspective, 13(2), 25-32.

Hartmann, A. (2006). The role of organizational culture in motivating innovative behaviour in construction firms. Construction Innovation: Information, Process, Management, 6(3), 159-172.

Hogan, S. J. ve Coote, L. V. (2014). Organizational culture, innovation, and performance: A test of schein's model. Journal of Business Research, 67, 1609-1621.

Hunt, S. D., Wood, R. V. ve Chonko, L. B. (1989). Corporate ethical values and organizational commitment in marketing. Journal of Marketing, 53(3, 79-90.

Hurt, H. T., Joseph, K. ve Cook, C. D. (1977). Scales for the measurement of innovativeness. Human Communication Research, 4, 58-65.

İșcan, F. Ö. ve Timuroğlu, M. K. (2007). Örgüt kültürünün iș tatmini üzerindeki etkisi ve bir uygulama. Atatürk Üniversitesi İktisadi ve İdari Bilimler Dergisi, 21(1), 119-135.

Işık, C. ve Meriç, S. (2015). Otel yöneticilerinin bireysel yenilikçi kapsamında değerlendirilmesi: Van ili örneği. Girișimcilik ve Inovasyon Yönetimi Dergisi, 4(1), 1-16.

Jacobs, R., Mannion, R., Davies, H. T. O., Harrison, S., Konteh, F. ve Walshe, K. (2013). The relationship between organizational culture and performance in acute hospitals. Social Science \& Medicine, 76, 115-125.

Karaca, T., Özkan, S. A. ve Küçükkelapçe, D. (2018). Determining the ethical climate perceptions of nurses' and midwives' in an obstetrics and pediatrics hospital. International Journal of Caring Sciences, 11(2), 006.

Karadut, G. (2014). Etik iklimin ve örgütsel adalet algzlarmm çalışanlarn iş tatminine etkisi: konaklama işletmelerinde amprik bir uygulama. (Yayınlanmamış Yüksek Lisans Tezi). Bahçeşehir Üniversitesi, Sosyal Bilimler Enstitüü, İstanbul.

Karcıoğlu, F. (2001). Örgüt kültürü ve örgüt iklimi ilişkisi. Atatürk Üniversitesi İktisadi ve İdari Bilimler Dergisi, 15(1-2), 265-283.

Kert, S. B. ve Tekdal, M. (2012). Comparison of individual innovativeness perception of students attending different education faculties. Gaziantep University Journal of Social Sciences, 11(4), 1150-1161.

Kılıç, H. (2015). İlkögrretim brans öğretmenlerinin bireysel yenilikçilik düzeyleri ve yașam boyu ögrenme eğilimleri: Deniz̨li ili örneği. (Yayınlanmamış Yüksek Lisans Tezi), Pamukkale Üniversitesi, Eğitim Bilimleri Enstitüsü, Denizli.

Kılıçer K. ve Odabaşı H. F. (2010). Bireysel yenilikçilik ölçeği: Türkçeye uyarlama, geçerlilik ve güvenilirlik çalışması. Hacettepe Üniversitesi Ë̈itim Fakültesi Dergisi, 38, 150-164.

Liu, Y., Zhao, S., Li, R., Zhou, L. ve Tian, F. (2018). The relationship between organizational identification and internal whistle-blowing: the joint moderating effects of perceived ethical climate and proactive personality. Review of Managerial Science, Volume 12(1), 113-134.

Lopez, T. B., Babin, B. J. ve Chung, C. (2009). Perceptions of ethical work climate and person-organization fit among retail employees in Japan and the us: A crosscultural scale validation. Journal of Business Research, 62, 594600.

Lyons, J. B. ve Schneider, T. R. (2005). The influence of emotional intelligence on performance. Personality and Individual Differences, 39, 693-703.

Meriç, S. ve Işık, C. (2015). Otel yöneticilerinin bireysel yenilikçi kapsamında değerlendirilmesi: Van ili örneği. Girişimcilik. ve Inovasyon Yönetimi Dergisi, 4(1), 1-16.

Meydan, C. H. ve Şeșen, H. (2015). Yapısal eşitlik modellemesi amos uygulamalar (2. Baskı). Ankara: Detay Yayıncılık.

Öcal, H. ve Ağca, V. (2010). Teknolojik değişim hızına bağlı olarak farklılaşan endüstri yapılarının örgüt kültürü ve işletme performansı üzerindeki etkileri. Ege Akademik Bakıs, 10(1), 157-182.

Oğuztürk, B. S. ve Türkoğlu, M. (2004). Yenilik ve yenilik modelleri. Doğu Anadolu Bölgesi Araştrrmalar, 3(1), 14-20.

Olpak, Y. Z., Arıcan, M. ve Baltacı, S. (2018). Öğretmen adaylarının öğrenme yaklaşımlarının ve bireysel yenilikçilik özelliklerinin akran öğretimine yönelik memnuniyetlerine etkisi. YYÜ Eğitim Faküiltesi Dergisi, 15(1), 525-551.

Özen, K. R., Özsoy, E., Karakiraz, A., Aras, M., Erol, E., ve Uslu, O. (2015). Örgüt kültürü çalışmalarının yöntem ve kapsam bakımından incelenmesi: Lisansüstü tezler üzerinden bir inceleme. Yönetim ve Ekonomi Arastormalarn Dergisi, 13(1), 123-142.

Özkalp, E. ve Kırel Ç. (2001). Örgütsel Davranıs. Eskişehir: Anadolu Üniversitesi Yayınları.

Robbins, S. P. (2003). Organisational behaviour (10 ${ }^{\text {nd }}$ Edition). NJ: Prentice-Hall Inc.

Rogers, E. M. (1983). Diffusion of innovations (3 ${ }^{\text {rd }}$ Edition). New York: The Free Publication.

Rogers, E. M. (1995). Diffusion of innovations. New York: Free Press.

Rogers, E. M. (2003). Diffusion of innovations. New York: Simon \& Schuster Press. 
Savran, G. (2007). Etik iklim ve tükenmislike sendromunun kalite yönetim sistemleri üzerine etkileri: Bir laboratuvar uygulaması. (Yayınlanmamış Yüksek Lisans Tezi). Dokuz Eylül Üniversitesi Sosyal Bilimler Enstitüsü, İzmir.

Schneider B., ve Rentsch J. (1988). Managing climates and cultures: A future perspective, in futures of organizations. Lexington, MA: Lexington Books, (In: Hage J, Editor), 181-200.

Schwepker, C. H., Ferrell, O. C. ve Ingram, T. N. (1997). The infulence of ethical climate and ethical conflict on role strees in the sales force. Akademiy of Marketing Science Journal, Spring, 25(2), 99-108.

Schwepker, C. H. (2001). Ethical climate's relationship to job satisfaction, organizational commitment and turnover intention in the salesforce. Journal of Business Research, 54 (1), 39-52.

Sökmen, A., Benk, O. ve Gayaker, S. (2017). Örgüt kültürü, örgütsel vatandaşlık davranışı ve örgütsel bağl1lik ilişkisi: Bir kamu kurumunda araştırma. Gaz̨i Üniversitesi İktisadi ve İdari Bilimler Fakültesi Dergisi, 19(2), 415-429.

Tewari, R. (2011). Individual innovation and orgnaziational success: Theoretical perspective. Review of Management, 1(2), 89-94.

Thurlings, M., Evers, A. T. ve Vermeulen, M. (2015). Toward a model of explaning teachers' innovative behavior: A literature raview. Review of Educational Research, 85(3), 430-471.

Toker, M. E. (2015). Tepe yöneticinin otantik ve etik liderlik davranıslarmm etik iklim algisına etkisi ve bir arastırma. (Yuiksek Lisans Tezi). Toros Üniversitesi Sosyal Bilimler Enstitüsü, Mersin.

Topcu, M. K., Gürsoy, A. ve Taşbaşı, B. (2013). Etik iklim algısının bireysel yenilikçilik davranışlarına etkisinde hizmetkar liderliğin rolü. 21. Ulusal Yönetim ve Organizasyon Kongresi. ss. 612-617.

Tsai, M. T., ve Huang, C. C. (2008). The relationship among etical climate types, facets of job satisfaction and three components of organizational commitment: A study of nurses in Taiwan. Journal of Business Ethics, 80(3), 565580 .

Valentine, S. ve Barnett, T. (2003). Ethics code awareness, perceived ethical values, and organizational commitment. Journal of Personal Selling \& Sales Management, 23(4), 359-367.

Victor B. ve Cullen J. B. (1988). The organizational basis of ethical work climates. Administrative Science Quarterly, 3(1), 101-125.

Weber J. ve Seger J. E. (2002). Influences upon organizational ethical subclimates: A replication study of a single firm at two points in time. Journal of Business Ethics, 41(1), 69-84.

West, M. A. ve Anderson, N. (1996). Innovation in top management teams. Journal of Applied Psychology, 81, 680-693.

West, M. A. ve Wallace, M. (1991). Innovation in health care teams. European Journal of Social Psychology, 21, 303-315.

Wimbush J. C., Shepard J. M. ve Markham S. E. (1997b). An emprical examination of the multi-dimensionally of the ethical climate in organizations. Journal of Business Ethics, 16(1), 67-77.

Wimbush, J. C, ve Sherpard, J. M. (1994). Toward an understanding of ethical climate: It's relationship to ethical behavior and supervisory influence. Journal of Business Ethics, 13, 637-647.

Yalçınsoy, A. ve Zincirkıran, M. (2016). Örgüt kültürü ve örgüt ikliminin örgütsel sessizlik üzerine etkisinin analizi. Scientific Cooperation for the Future in the Social Sciences International Conference, 22-23 September, Uşak.

Yaman, E. ve Ruçkar, K. (2014). Örgüt kültürünün yordayıcısı olarak üniversitelerde örgütsel sessizlik. Yükesekögretim ve Bilim Dergisi, 4(1), 36-50.

Yuan, F. ve Woodman, R. W. (2010). Innovative behavior in the workplace: The role of performance and image outcome expectations. Academic Management Journal, 53(2), 323-342.

Yücel, İ. ve Koçak, D. (2016). Örgüt kültürü ile personel güçlendirme arasındaki ilişkiye yönelik bir araştırma. Kafkas Üniversitesi İktisadi ve İdari Bilimler Fakültesi Dergisi, 7(12), 1-24.

\section{EXTENDED ABSTRACT}

Businesses can achieve their goals and create value in line with their ethical values. In an institution where ethical rules do not exist and are not developed, serious problems may be experienced in the application of these rules. Ignoring the rules of ethics will give financial and moral losses for the company (Celik, 2015). Managers need to manage the ethical values of the institutions they work for (Akbas,2010).

Ethical climate is defined as the determination of how to deal with the ethical problems faced by organizations and what is right and wrong in the process by written, formal or informal rules, and perceiving the ethically correct behavior in the organization in general (Victor ve Cullen, 1988). Ethical climate responds to the question of "what should I do" in the face of the unethical situation faced by the employees and helps to solve the problems (Cullen, Parboteeah ve Victor, 2003) and to create and explain the ethical behaviors in the organizations (Wimbush, Shepard ve Markham, 1997). The existence of an ethical climate in organizations leads to high motivation of employees (Dickson, Simith, Grojean ve Ehrhart, 2001), job satisfaction and increase of company performance(Weber ve Seger, 2002; Tsai ve Huang, 2008), organizational commitment and reduction of layoffs (Schwepker, 2001; Valentine ve Barnett, 2003; Hunt, vd. 1989). Organizational culture is defined as the system of behaviors, beliefs and values that reveal the ideas and thoughts of an organization's employees (Karcioglu, 2001; Yaman ve Ruclar, 2014). At the same time organizational culture provides convenience reduction of uncertainty in 
terms of employees and work done how and what way. Employees should adopt the organizational culture, and they should be a part of the organization. Employees who exhibit appropriate attitudes and behaviors towards organizational culture, receive awards and promotions (Robbins, 2003). In the literature research, the most common classification of organizational culture was found to be four sub-dimensions: clan culture, market culture, hierarchy culture and adhocracy culture (Yalcinsoy ve Zincirkiran, 2016). Individual creativeness refers to the situations in which risk-taking individuals against new thing, acceptance, adaptability, tolerance and and be open to experience against what is new (Demiraslan ve Usluel, 2008). Individual creativeness is linked to the creativity of the individual. People can be trained to think more creatively and implement creative thinking strategies (Tewari, 2011).

It is aimed to determine the moderating role of organizational culture in the influence of ethical climate perception of scholars on individual innovation. The population of the study consists of approximately 300 academic staff of a higher education institution in Konya. The questionnaire method was used to collect data from 207 participants with convenience sampling method. Research hypotheses, H1: Ethical climate perception has an impact on individual innovation, H2: Organizational culture has a regulatory role in the impact of ethical climate perception on individual innovation. The results of the reliability analysis (Ethical Climate Perception: ,931; Individual Innovation:, ,829; Organizational Culture: ,955 and its sub-dimensions Adhocracy Culture: ,926; Clan Culture: ,920; Market Culture: ,881; Hierarchy Culture: ,903) were examined. According to the results of Pearson correlation analysis (ethical climate perception and individual innovation $(\mathrm{r}=, 352, \mathrm{p}>0.01)$, ethical climate perception and organizational culture $(r=, 466, p>0.01)$, individual innovation and organizational culture $(r=189, p>0.01)$ a statistically significant relationship was found between the variables. In the confirmatory factor analysis, the Composite Reliability (CR) coefficients should be 0.70 and above to ensure a valid structure. CR value for the variables used in the study is over 0.70. In terms of factor loadings, it can be stated that the variables used in the research have values above or below the ideal structure. According to the results of hierarchical regression analysis, In Model 1, it was found that the relationship between independent variable ethical climate perception and dependent variable individual innovation behavior was significant and positive $(\beta=0,352, p<0,05)$. In Model 2 , it was found that the perception of ethical climate had an influence on individual innovation $(\beta=0,337, \mathrm{p}<0,05)$, but organizational culture had no influence on individual innovation $(\beta=0,032, \mathrm{p}<0,05)$. When model 3 is examined, the interaction variable obtained by multiplying the values of ethical culture and organizational culture (Ethical Climate Perception*Organizational Culture) which is the regulatory variable is added to the analysis. The amount of variance explained was increased from $\mathrm{R} 2=0,125$ to $\mathrm{R} 2=0,247$ in the third model by the addition of the term interaction. Ethical climate perception and organizational culture interaction had a positive and significant influence on individual innovation $(\beta=0,373, \mathrm{p}<0,05)$. In this context, H2 is accepted. The results of the research are supported by the literature in which employees' ethical climate perceptions affect individual innovative behaviors (Akkoc, 2012; Topcu, Gursoy and Tasbasi, 2013). In line with these results, it can be stated that academics are informed by their managers about ethical behaviors that cause positive attitudes and behaviors. Furthermore, the existence of an ethical climate can positively affect the performance and motivation of academicians. It can be said that this will have a direct and indirect impact on individual innovation. Determining and applying ethical climate rules according to organizational activities can be efficient for employees, managers and organization. 